\title{
Recurrent ectopic pregnancies with secondary infertility: a case report
}

\author{
Shivangi Jain ${ }^{1 *}$, Indu Verma ${ }^{2}$
}

\begin{abstract}
${ }^{1}$ Department of Obstetrics and Gynecology, MMIMSR, Mullana, Haryana, India
${ }^{2}$ Department of Obstetrics and Gynecology, CMC, Ludhiana, Punjab, India
\end{abstract}

Received: 14 April 2020

Accepted: 05 May 2020

\section{*Correspondence:}

Dr. Shivangi Jain,

E-mail: shivangijain2393@gmail.com

Copyright: (C) the author(s), publisher and licensee Medip Academy. This is an open-access article distributed under the terms of the Creative Commons Attribution Non-Commercial License, which permits unrestricted non-commercial use, distribution, and reproduction in any medium, provided the original work is properly cited.

\begin{abstract}
Infertility is defined as 1 year of unprotected sexual intercourse without pregnancy. It is further classified as primary and secondary. Secondary infertility is one in which prior pregnancy not necessarily live birth has occurred. Pelvic infections as a cause for infertility are seen in $12 \%$ cases while genital tuberculosis contribute 10-15\%. Various studies have well established a relationship between subclinical infection and infertility with the two most potential pathogens being: Chlamydia trachomatis and mycoplasma species. Authors are presenting two cases one of a 30yr female, P0+5, with class 2 obesity with previous three ectopic pregnancies with LSO done 1 year back i/v/o left ruptured ectopic now presenting with secondary infertility for 1 year and another case of a 21 years female, P0+2, with previous two ectopic with LSO done 2 years back now presenting with infertility. These cases emphasize that infections are important causes for recurrent ectopic pregnancies and infertility.
\end{abstract}

Keywords: Chlamydia trachomatous, Genital tuberculosis, Infertility, Pelvic infections, Recurrent ectopic pregnancies, Recurrent spontaneous abortions, Salpingo oophorectomy

\section{INTRODUCTION}

Infertility is defined as 1 year of unprotected sexual intercourse without pregnancy. Secondary infertility is one in which prior pregnancy not necessarily live birth has occurred. Causes contributing to secondary infertility:

- Infections

- Spontaneous abortions

- Impaired sperm production, function or delivery in men

- Fallopian tube damage

- Complications related to prior pregnancies or surgery

Genital tuberculosis in females constitutes $1 \%$ of all gynecological admissions. ${ }^{1}$ Genital TB mostly occurs secondary to pulmonary TB (via haematogenous route). Fallopian tubes are affected in $100 \%$ cases followed by endometrium in $50 \%$. The most common presentation of genital TB is infertility $\mathrm{f} / \mathrm{b}$ abnormal menstruation. The chances of pregnancy in females suffering from genital TB have been poor (5\%) even after the completion of treatment. Pelvic infections as well as genital tuberculosis have found to increase the risk of ectopic pregnancy by $6-$ 10 folds. 1 According to a recent study genital tuberculosis was found to be responsible for $13.2 \%$ of all the cases of ectopic pregnancies included in the study, establishing genital $\mathrm{Tb}$ as an important cause of ectopic pregnancy in India. ${ }^{2}$ Among women with history of previous ectopic the risk of recurrent ectopic pregnancy ranges from $10-27 \%$, approximately 5-10 times the general population risk for ectopic pregnancy. ${ }^{3,4}$

\section{CASE REPORT}

\section{Case 1}

A 30 years old female P0L0A5 came to the hospital with c/o inability to conceive for 1 year following recurrent pregnancy losses. 
Previous $M / H$ : No h/o any menstrual irregularities.

\section{Obstetrics h/o: P0L0A5}

- A1: 5 years back, Rt. tubal ectopic, managed conservatively.

- A2: 4.5 years back, spontaneous abortion at 1.5 months POG not $\mathrm{f} / \mathrm{b} \mathrm{d}$ and $\mathrm{e}$.

- A3: 4 years back, spontaneous abortion at 8 days of pregnancy (UPT+ve) not $\mathrm{f} / \mathrm{b} \mathrm{d}$ and $\mathrm{e}$.

- A4: 2 years back, Rt. tubal ectopic, managed conservatively.

- A5: 1 year back, ruptured Lt. Tubal ectopic f/b LSO.

Medical h/o: H/o of PID, no h/o tuberculosis in past.

Family h/o: Not significant.

Personal h/o: non-alcoholic, non-smoker, no drug addiction, no h/o any sexual dysfunction.

\section{On examination}

The patient was found to have a BMI of 38 (class 2 obesity). Her vitals were stable. Abdominal examination was s/o obesity and showed a mid-line scar of laparotomy. P/S, P/V examinations were not significant.

\section{Routine Ix}

$\mathrm{Hb}: 12.4$, Rbs: 102, Rft: wnl, urine routine: pus cells 2-3, albumin: trace, viral markers: NR, thyroid profile: normal

\section{Special Ix}

ESR - $90 \mathrm{~mm}$ at $1^{\text {st }}$ hour, APLA: negative, lipid profile: total cholesterol $-163 \mathrm{mg} / \mathrm{dl}$, S. prolactin: $12.61 \mathrm{ng} / \mathrm{m}$, USG: endometrial thickness was $5 \mathrm{~m}$, endometrial biopsy: endometrial curetting was s/o late secretory endometrium, endometrium for AFB: no acid-fast bacilli.

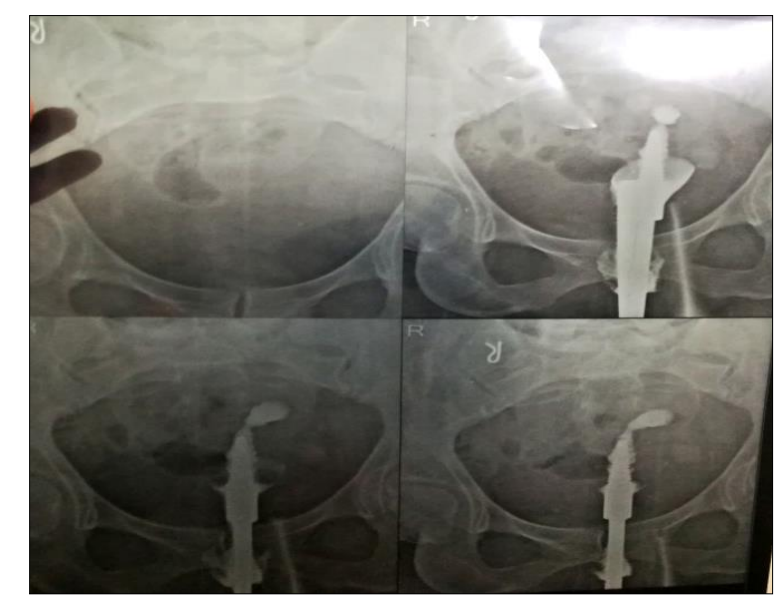

Figure 1: Right sided uterine cornual block with left side post salpingectomy on hsg.
Mantoux test: $8 \mathrm{~mm}$ (equivocal/doubtful), Husband serum analysis: wnl, Chest X-ray: showed a normal study, CBNAAT for menstrual aspirate was sent, which was negative. HSG showed features s/o corneal block with left side post salpingectomy (Figure 1).

\section{Diagnosis reached}

A total 30 years, P0A5 with previous 3 ectopic pregnancies with recurrent pregnancy loss with female factor secondary infertility.

\section{Case 2}

A 24 years old female, POL0A2, came to the hospital with c/o inability to conceive for 6 months and irregular menses for past 2 months prior to admission.

Previous $M / H$ : no $\mathrm{h} / \mathrm{o}$ any menstrual irregularities in past.

Obstetrics h/o: P0L0A2.

- A1: 2.5 years back, ruptured Lt. tubal ectopic $\mathrm{f} / \mathrm{b}$ exp. laprotomy with LSO.

- A2: 6 months back, Rt. unruptured ovarian ectopic $\mathrm{f} / \mathrm{b}$ ovariotomy.

Medical h/o: - No h/o tuberculosis, Pt. Took t/t for primary infertility

Family h/o: not significant.

Personal h/o: not significant.

\section{On examination}

Patient`s vitals were stable, abdominal examination showed a mid-line linear scar of laparotomy, $\mathrm{p} / \mathrm{s}$ and $\mathrm{p} / \mathrm{v}$ examination were not significant.

\section{Routine Ix}

Hb: 11.5 gm\%, Rbs: 60 mg/dl Rft: wnl, urine routine: pus cells: 3-4, albumin: nil, sugar: nil, viral markers: NR, thyroid profile: normal.

\section{Special Ix}

ESR: $30 \mathrm{~mm}$ at $1^{\text {st }}$ hour, bhcg: 2.5 , serum prolactin: normal range, USG: ET - $7 \mathrm{~mm}$, Rt adnexal hemorrhagic cyst $3.8 \times 3.8 \mathrm{~cm}$, endometrial biopsy: endometrial glands in early proliferative phase with no evidence of granuloma/malignancy, endometrium for AFB: growth of mycobacterium other than tuberculosis obtained. No acid fast bacilli seen, sputum for gram staining: gram positive cocci in chain s/o normal flora seen, no gram negative organism seen, sputum for $\mathrm{C} / \mathrm{S}$ : growth of normal flora, sputum fluorescent microscopy: negative for acid fast bacilli, husband serum analysis: wnl, chest X-ray: 
showed a normal study, HSG findings were s/o right hydrosalpinx most likely tubercular with left side post salpingectomy (Figure 2).

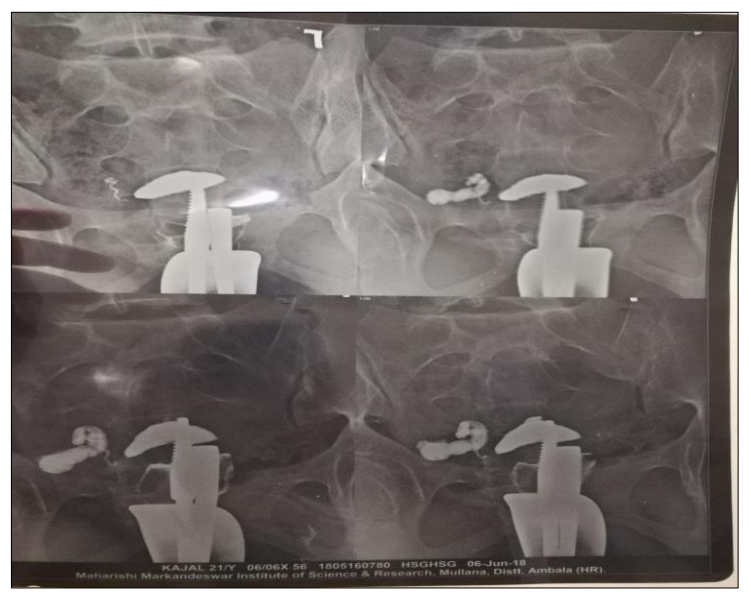

Figure 2: Right hydrosalpinx with left side post salpingectomy on hsg.

\section{Diagnosis reached}

A total 24 years P0A2 with previous two ectopic with female factor infertility.

\section{Further plan of management}

The patient was diagnosed as a case of NTM uterus and started on: Tab rifampicin $600 \mathrm{mg}$, Tab ethambutol 1200 $\mathrm{mg}$, Tab clarithromycin $500 \mathrm{mg}$, Inj amikacin $750 \mathrm{mg}$, for an IP of 3 months and a CP of 12 months.

\section{DISCUSSION}

Significant history of pelvic infection, spontaneous abortions and previous ectopic pregnancies are major risk factors for ectopic pregnancies and in turn infertility. ${ }^{5}$ Maternal age and incidence of ectopic pregnancy has a direct relation. The appropriate treatment of a nonruptured ectopic pregnancy could be medical management with methotrexate or surgery. ${ }^{6}$ Laparatomy is the main method of surgery which is still used. ${ }^{7}$

Multi drug anti-TB drugs are still the mainstay of treatment for genital TB with surgery being the option in advanced cases. A culture positive specimen or a positive histology report is the mainstay requirement for the diagnosis of genital TB. The two main imaging modalities for diagnosis of genital TB are USG and HSG. $^{8}$

Although laparoscopy is an invasive procedure but a combination of laparoscopy and hysteroscopy is preferred as it allows visual inspection of ovaries, fallopian tube and peritoneal cavity in suspected cases of genital TB.
Chlamydia trachomatis serum antibodies, antibodies to a Chlamydia sarkosyl-soluble 57-kDa protein are important serological test for making a diagnosis of PID as a cause of ectopic pregnancy and infertility. ${ }^{9}$

Recurrent ectopic pregnancies as a long-term complication of ectopic pregnancy can impair subsequent fertility and negatively affect the quality of life. ${ }^{10}$

\section{CONCLUSION}

The case report involved a rare situation were multiple episodes of ectopic pregnancies finally ended up with patient presenting with secondary infertility. The case report clearly indicates a previous history of pelvic inflammatory disease and/or mycobacterium infections as a major factor towards the increased incidence rate of the ectopic pregnancy and infertility in our country.

\section{Funding: No funding sources \\ Conflict of interest: None declared \\ Ethical approval: Not required}

\section{REFERENCES}

1. Malhotra N, Kumar P, Malhotra J, Bora NM, Mittal P. Jeffcoate's principles of gynaecology. Eighth International Edition. Jaypee Brothers Medical Publishers (P) Ltd.; 2014.

2. Sharma JB, Naha M, Kumar S, Roy KK, Singh N, Arora R. Genital tuberculosis: an important cause of ectopic pregnancy in India. Indian $\mathbf{J}$ Tuberc. 2014;61(4):312-7.

3. Butts S, Sammel M, Hummel A, Chittams J, Barnhart K. Risk factors and clinical features of recurrent ectopic pregnancy: a case control study. Fertil Steril. 2003;80:1340-4.

4. Kuroda K, Takeuchi H, Kitade M, Kikuchi I, Shimanuki H, kumakiri J, et al. Assessment of tubal disorder as a risk factor for repeat ectopic pregnancy after laparoscopic surgery for tubal ectopic. J Obstet Gynecol Res. 2009;35:520-4.

5. Yadav A, Gupta V, Patel S. Recurrent ectopic pregnancy after ipsilateral salpingectomy: a rare case report, Int J Reprod Contraceptive Obstet Gynecol. 2015;4(5):1615-7.

6. Lozeau AM, Potter B. Diagnosis and management of ectopic pregnancy. Am Fam Physician. 2005;72(9):1707-14.

7. Tabandeh A, Besharat M. Recurrent ectopic pregnancies in fallopian tube: a case report. J Clin Diagnos Res. 2012;6(3):493-4.

8. Sharma JB, Dharmendra S, Agarwal S, Sharma E. genital tuberculosis and infertility. Fertil Sci Res. 2016;3(1):6.

9. Brunham RC, Peeling R, Maclean I, Kosseim ML, Paraskevas M. Chlamydia trachomatis-associated ectopic pregnancy: serologic and histologic correlates. J Infect Dis. 1992;165:1076-81. 
10. Stulberg DB, Zhang JX, Lindau ST. Socioeconomic disparities in ectopic pregnancy: predictors of adverse outcomes from Illinois hospital-based care, 2000-2006. Matern Child Health J. 2011;15:234-41.
Cite this article as: Jain S, Verma I. Recurrent ectopic pregnancies with secondary infertility: a case report. Int J Reprod Contracept Obstet Gynecol 2020;9:2587-90. 